\title{
Space, Behavior, and Environmental Perception in Open Plan Offices: A Prospective Study
}

(Environment and Planning B: Planning \& Design. In Press)

\author{
AUTHORS \\ Mahbub Rashid, PhD, AIA \\ Department of Design, University of Kansas, 1467 Jayhawk Boulevard, Room 300, Lawrence, \\ Kansas 66045, USA; e-mail: mrashid@ku.edu \\ Jean Wineman, DArch \\ Taubman College of Architecture and Urban Planning, University of Michigan, Room 2150, \\ 2000 Bonisteel Boulevard, Ann Arbor, MI 48109-2069, USA; e-mail: jwineman@umich.edu
}

Craig Zimring, $\mathrm{PhD}$

College of Architecture, Georgia Institute of Technology, 245 Fourth Street, Atlanta, GA 30332-155, USA; e-mail: craig.zimring@arch.gatech.edu

Authors' Note: This research was made possible by a contract from the US General Services Administration (GSA). The authors would like to thank the unknown reviewers for their comments on the manuscripts of the paper. For questions or comments about this article, write to Mahbub Rashid at mrashid@ku.edu. 


\title{
Space, Behavior, and Environmental Perception in Open Plan Offices: A Prospective Study
}

\begin{abstract}
This prospective research study was conducted at a government office, which moved from an open plan office with somewhat enclosed workspaces to another open plan office with open workspaces. The study at the old office was conducted almost one year before the move, and the study at the new office was conducted more than one year after the move. The purpose of this study was threefold: (1) to measure and evaluate changes in patterns of accessibility and visibility due to changes in office layout, (2) to understand the effects of layout changes on observed behaviors, and (3) to determine the effects of layout changes on environmental perception. The study included the analysis of visibility and accessibility of each layout using space syntax techniques, field observations of behaviors, and questionnaire surveys of employees' perception of privacy, job satisfaction and commitment to organization. During field observations, movement, visible copresence (i.e., the number of people visible from a space) and face-toface interaction were observed along a predefined route in each office. Thirty-five people responded to the questionnaire survey at the old office. Out of 35, only 29 were available for survey at the new office. Based on the questionnaire survey data, three multi-item scales were constructed to measure perceived privacy, job satisfaction and commitment to organization. Results indicate better visibility and accessibility, increased face-to-face interactions, and improved perceived privacy at the new office. Results also show consistent effects of space on movement, and significant positive correlations between perceived privacy, job satisfaction and commitment to organization at these locations despite significant design differences. Implications of the research results and limitations of the research design are discussed.
\end{abstract}

Keywords: Open Plan Office, Space Syntax, Movement, Copresence, Face-to-face Interaction, Privacy, Job Satisfaction, Commitment to Organization

Research Setting: Workplace/Office 


\section{Introduction}

Office layout, i.e., the arrangement of workplaces and types of boundaries in an office, is an important dimension of office environment (Oldham et al., 1995; de Croon et al., 2005). Changes in office layout may affect an organization in different ways. At the very basic level, layout changes may affect accessibility and visibility within an office affecting individual and organizational behaviors. They may also affect user attitude and perception of the work environment because of their effects on behavior. The literature on both environmental design and behavior has extensively discussed the nature and importance of these effects (for literature review, see de Croon et al., 2005; Gifford, 1997, 2002; McCoy, 2002; Mittleman, 1996; Oldham et al., 1995; Rashid \& Zimring, 2005; Wineman, 1982; Sundstrom, 1987).

Among the reported studies, Sundstrom et al. (1980), Marans and Spreckelmeyer (1982), Zalesny and Farace (1987), Cangelosi and Lemoine (1988), and Brennan et al. (2002) are particularly relevant to the current study, for they compare the effects of traditional vs. open plan offices on different aspects of environmental design and behavior. However, none of these studies reports the effects of different open plan offices on behavior and perception of office workers. This is important because variations in open plan offices can be quite significant. While all open plan offices are characterized by an absence of floorto-ceiling walls, the extent to which these offices provide private, identifiable and defensible work areas for an employee may vary significantly. For example, in some open plan offices modular furniture with somewhat permanent enclosing partitions can reduce visibility and accessibility significantly. In contrast, in other open plan offices an arrangement of easily movable partitions, screens, office furniture, and/or plants can help delineate individual work areas and functional spaces that often cannot restrict visibility and accessibility.

The purpose of this prospective study is to investigate the effects of different types of open plan offices on workers' behavior and perception. Our basic hypothesis here is that patterns of visibility and accessibility are different in different open plan offices (Hypothesis 1). We are interested in visibility and accessibility patterns, because studies show that they can affect the ways in which individuals use office spaces (Bechtel, 1976; Hall, 1966; Hillier \& Penn, 1991, 1992; Parsons, 1976; Penn et al., 1997). Studies also show that these patterns can affect observed levels of interaction and eagerness to travel for interaction at workplaces (Hillier \& Grajewski, 1987; Grajewski, 1992).

We are also interested in comparing the effects of visibility and accessibility patterns on spatial behaviors in different open plan offices, since the published literature does not report any study on the topic. Regarding spatial behaviors in offices, we believe that movement, visible copresence (i.e., the number of people seen from any space), and face-to-face interaction are important. That is because increased movement and visible copresence may provide increased opportunities for face-to-face interaction, and we know from the literature that face-to-face interaction may help build trust among office workers leading to improved office performance (Allen, 1977; Cross and Borgatti, 2002; Sundstrom and Altman, 1989; Wineman and Serrato, 1998). More recently, Rashid et al. (2006) report a study investigating the relationships among movement, visible copresence, and face-to-face interactions. 
We hypothesize that an open plan office with better visibility and accessibility may help generate more face-to-face interaction because of their positive effects on visible copresence and movement (Hypothesis 2). We also hypothesize that in such an open plan office face-to-face interaction may not increase equally at all locations (Hypothesis 3). For example, interaction may decrease in circulation spaces of the office, because sometimes it is uncomfortable to interact in circulation spaces that are an integral part of workspaces. Additionally, we hypothesize that although movement, face-to-face interaction, and visible copresence may increase in an open plan office with better visibility and accessibility, the underlying effects of space on the distribution of these behaviors may remain similar in any open plan offices. In other words, despite varying degrees of visibility and accessibility, we may find more movement, visible copresence, and face-to-face interaction in more accessible spaces in all open plan offices (Hypothesis 4).

Should open plan offices differ in the ways we hypothesize above, then because of these differences we may expect changes in social and/or sociotechnical relations in a work environment. A social relations perspective suggests that an environment may act as a catalyst for social interactions and communications affecting organizational climate (Oldham \& Brass, 1979). The origin of the social relations perspective can be traced to two different but interrelated social psychological research streams. The first stream argues that the physical environment can shape the social interaction patterns of individuals (Festinger, Schacter, and Back, 1950; Gullahorn, 1952; Holahan and Saegert, 1973; Homans, 1950, 1954; Powell, 1952; Whyte, 1956). Festinger, Schacter, and Back (1950) report the classic study demonstrating this effect. They show that interaction among residents in an apartment complex is highest when there is only one stairway at the end of the floor of the apartment building. In other words, according to this perspective people are most likely to interact and communicate with others when the physical environment encourages them to do so. Other studies show that proximity of workspaces may predispose the development of an informal group among compatible people (Gullahorn, 1952; Walker \& Guest, 1952); and that spatial arrangement and the location of walls, partitions, furnishings, and other barriers may affect cohesiveness and interaction among groups (Lawrence \& Lorsch, 1967; Bobele \& Buchanan, 1979).

Building on the first stream, the second social psychological research stream suggests that the physical characteristics of settings can influence interaction, which, in turn, contributes to individual attraction and organizational climate. This stream is essentially based on the research work that suggests that higher interaction among persons produces better interpersonal attraction (e.g., Bovard, 1951; Gullahorn, 1952). Bovard, for example, shows higher positive effects in groups with higher member-to-member interactions. The expected relationship between interaction and organizational climate, however, is less direct. Proponents of the social relations perspective argue that interaction increases attraction, which is an essential condition for improved organizational climate. For example, Berkowitz (1956) reports a significant positive relationship between aircrew members' attitudes toward one another and their combat effectiveness. Likewise, Chapman and Campbell (1957) report that an individual's desirability as a teammate is significantly correlated with the success of her team.

According to the social relations perspective, then, an open plan office with more open workspaces should help improve organizational climate/environment as an outgrowth of the informal communication associated with proximity, visibility and accessibility, an issue Zalensy and Farace (1987) study in relation to traditional and open offices. Following their logic, we hypothesize that an open plan office 
with better visibility and accessibility will have positive effects on one's job satisfaction (Hypothesis 5) and on one's commitments to her organization (Hypothesis 6). Hypotheses 5 and 6, then, may lead to another hypothesis that suggests perceived job satisfaction and commitment to organization may be correlated with one another (Hypothesis 7).

In contrast to the advocates of the social relations perspective, the advocates of the sociotechnical perspective of social psychological research take a more critical position regarding the effects of the physical environment. For them, an apparently favorable physical setting may not always encourage interaction as assumed by social relations advocates for the setting may have other unintended psychosocial consequences. Whereas the advocates of social relations see physical boundaries as deterrents to interaction, for the advocates of the sociotechnical perspective the presence of physical boundaries can transform a work area into a private, defensible space. As a result, an individual may experience a greater sense of privacy. Such a private area may also provide opportunities for personal conversations and the sharing of information. Additionally, it may reduce the likelihood of external intrusions (Gyllenhammar, 1977). Furthermore, a bounded work area clarifies for employees the nature of the work process (Rice, 1958; Cummings and Griggs, 1976). Consistent with this perspective, Oldham and Brass (1979) report that employee satisfaction and internal motivation decreased significantly after employees moved from a conventional office to an open-plan office.

As a result, a sociotechnical perspective of the effects of an open plan office with better visibility and accessibility can be complex and can often contradict that of a social relations perspective. For example, if an open plan office diminishes perceived personal privacy and opportunities for close personal relationships that come with having personal privacy, then individuals' job satisfaction may diminish. However, accessibility and visibility are not the only components that determine perceived privacy at workplaces. At workplaces, auditory privacy can be as important as physical and visual privacy. In other words, a higher sense of perceived privacy may prevail even in an open plan office if auditory privacy can be ensured. Therefore, from a sociotechnical perspective we hypothesize that, a social relations perspective, which suggests that an open plan office with more visibility, accessibility and openness may improve one's job satisfaction and one's commitments to her organization, should work only in situations where the open plan can ensure one’s sense of privacy (Hypothesis 8).

\section{Case Studies}

The study was conducted at the old and new open plan offices of a public real estate organization (Figures 1a \& 1b). The organization has several departments. Each department of the organization performs different functions, and each has several groups working on different projects. The nature and intensity of communications within and across these groups vary depending on the types of projects these groups perform at any particular time. As a result, any simple generalization about the nature and pace of work in the organization cannot be made.

The building that housed the old office and the building that houses the new office are located in close proximity in the downtown of a major metropolitan area. Consequently, no major change occurred in the population of the organization after the move to the new location. The organization occupied three floors 
of the building at each location, but only one floor that was occupied by the same departments at each location was included in this study.

The old open plan office of the organization had a rectilinear layout. Different departments of the organization were clearly separated in the layout. Little effort was made to integrate these departments using common public and/or semi-public spaces with common amenities. Most often, the common areas of the office were located at the furthest corners of the layout with little or no connection to those corridors that appeared to be used most. Most mangers had private offices with windows around the perimeter, while other individual workspaces were clustered in the center of the office. These individual workspaces were private and/or semi-private, and were defined by modular furniture systems and high, solid, non-transparent partition walls. Though these partition walls did not extend from floor to ceiling, they were high enough to provide these workspaces a fair amount of visual and acoustic privacy.

Apparently, the leadership of the organization, who had set a goal to improve interaction and collaboration within as well as across groups and departments, argued that the old layout had failed to support their goals. They also argued that a lack of spatial resources for collaboration in the old layout had negatively impacted employee morale leading to less-than-expected job satisfaction and commitment to the organization. Consequently, they embarked on designing the new open office not only to reinforce the already existing patterns of informal communication but also to create other new patterns.

The new office, which has an organic layout with no apparent geometric order, is somewhat similar to the so-called landscape office. Here, departments have no partitions separating them from one another. Public and/or semi-public territories have a wide variety of features, including kitchens, refrigerators, central service hubs, recreational facilities, comfortable furniture, and attractive lounge-like spaces. Managers are collocated with other workers on the floor. Individual workspaces are open and relatively small. Circulation spaces, which weave through these workspaces, lack definitions and often become an integral part of workspaces.

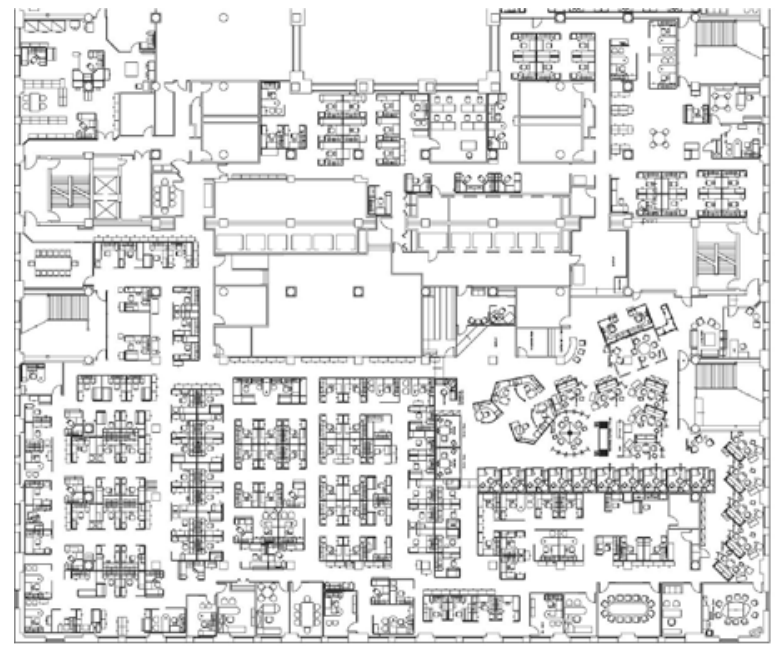

Figure 1a: The layout of the old office.

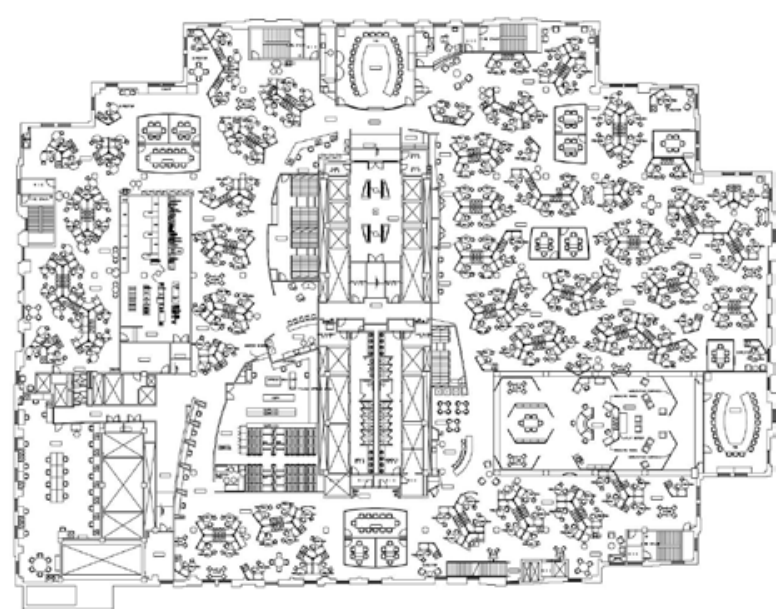

Figure 1b: The layout of the new office. 


\section{Methods}

\section{Overview}

The study at the old office environment was conducted about one year before the organization moved into the new office. To eliminate any residual effects and recalls, the study at the new office was conducted more than one year after the move. The study at these sites included layout analysis, field observation, and questionnaire survey using the same analytic techniques, observation methods, and survey instruments.

\section{Layout Analysis}

We analyzed the visibility, accessibility, and interconnectedness of the layouts using the spatial descriptors derived from space syntax theories and methods (Figures 2a \& 2b). Space syntax provides rigorous methods for characterizing the overall building layout (for details of the theories and techniques, see Hillier \& Hanson, 1984; Hillier, 1996). For our purpose, the layout of each office was represented as a set of the minimum number of longest sight lines needed to cover every space and to complete every circulation ring in the layout. In the space syntax literature, each of these sight lines is known as an axial line, and the complete set of lines covering a layout as an axial map. An axial map provides a rigorous way to describe how we see and move in a layout. Its importance lies in the simple facts that, in space, individuals prefer to move along a straight-line as represented by an axial line unless there is a reason not to do so; and that the way individuals move in space is very often defined by the number of choices available from their line of movement as represented by the number of intersections of an axial line with other axial lines.

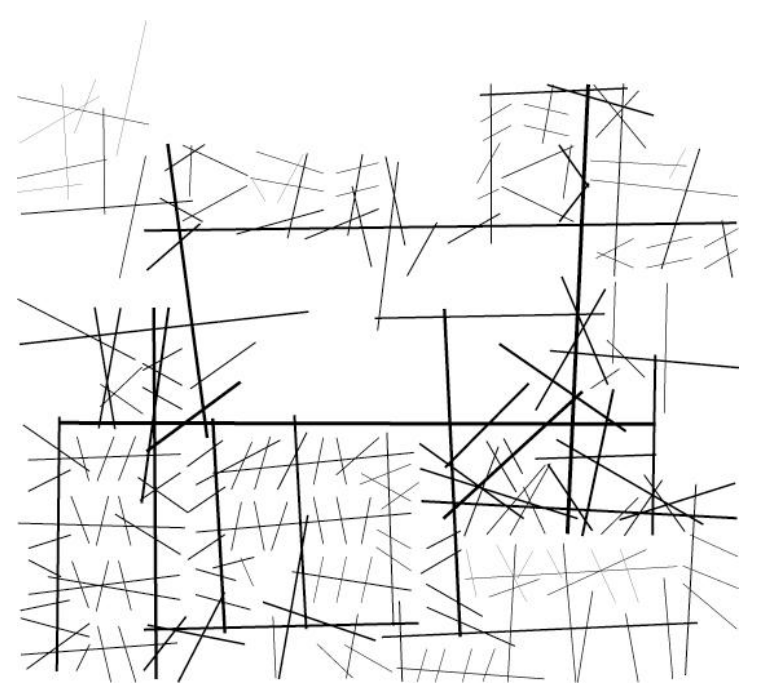

Figure 2a: The axial map of the old office.

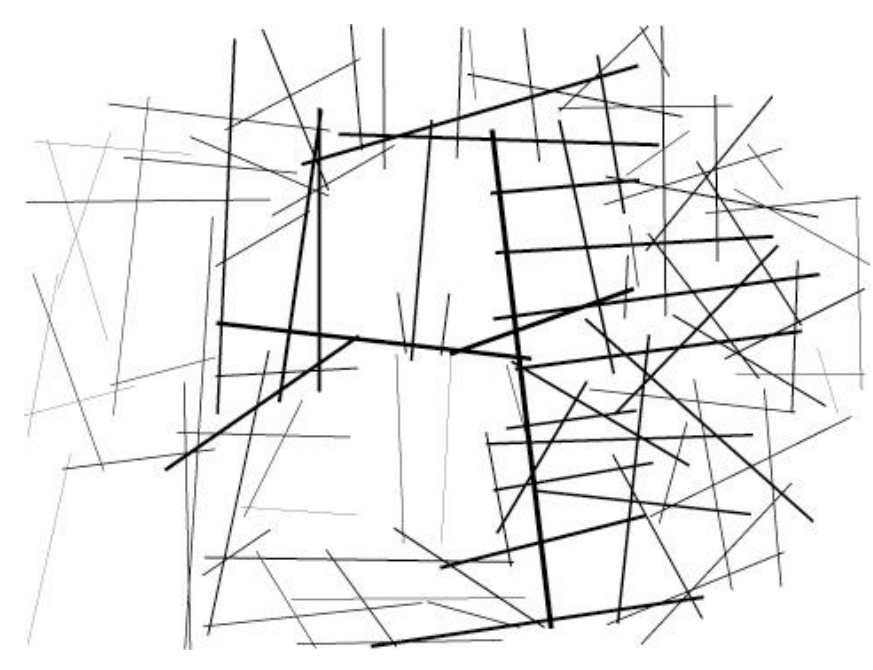

Figure 2b: The axial map of the new office.

Note: These axial maps show the distribution of integration values using line thickness. The thick lines are more integrated than the thin lines. 
Following the space syntax theories, the "Spatialist" computer program, developed at Georgia Tech, was used to assess the relational pattern of the axial lines in an axial map (Peponis et al. 1998, 1998a, 1997). Two important descriptors of interconnectedness of the axial structure, connectivity and integration, were used in our study. Connectivity of an axial line is the number of axial lines directly connected to the line. Connectivity, a local property of an axial line, is interesting because it describes the degree of choice present on the line: Higher connectivity means more choices of movement from the line. Integration, on the other hand, is a global property describing the connectedness of an axial line to all other axial lines of an axial map: Higher integration of an axial line means that the line is easily accessible. The length of axial lines, representing the reach of the visual field of a space, was also used in the study to describe the degree of visibility available from the space.

\section{Behavior Observation}

We observed three different behaviors along a predetermined route covering different types of spaces (i.e., spaces with different functions and integration values) in each office. The route was composed of several linear segments of the axial map of an office layout (Figure 3a). A field observer observed the following three behaviors at each office as she walked along the path at a regular pace:

1) Movement (defined as the number people moving on any segment of the route). In this case, the observer was instructed to record anyone moving within an imagined band of space along her path. This band of space did not include any part of a workspace (Figure $\mathbf{3 b}$ ).

2) Face-to-face interaction (defined as the number of people seen engaged in face-to-face interactions on a route segment as well as in the workspaces along the segment). In this case, the observer was instructed to record any interaction involving two or more people not only within an imagined band of space along her path but also within the workspaces directly connected to this band of space (Figure 3c).

3) Visible co-presence (defined as the number of people, active and/or inactive, visible from any segment of the route). In this case, the observer was instructed to record the total number of people located within the visual field drawn from a route segment at the eyelevel of an average person (Figure 3d).

For recording purposes, we used the up-to-date layout of each office with the route drawn on it. In total, 20-30 rounds of observations were made along any given route during different times of a workday over a period of three days. The data was then manually entered into a spreadsheet for further analysis. Figures 4a \& 4b show the observation routes in the two offices under investigation. For analysis purposes, we normalized the observation data for 100' (30.48m)-long segments to remove the differential effects of the length of route segments on movement, face-to-face interaction and visible co-presence. This was done primarily because our units of observation were linear route segments, and our descriptors of spatial layout were related to these route segments. However, unlike movement, interaction and copresence occur not in linear spaces but mostly in spaces with 2-D extension. For future work, it may then be more appropriate not only to describe a layout using 2-D spatial units, but also to normalize interaction and copresence by units of area.

Regarding our behavior observation technique, it is worth noting that this is a modified version of the fixed route moving observer method of data gathering used in earlier space syntax studies involving urban as well work environments. More recent space syntax studies, however, use snapshots observations of all 
areas of work environments. This method, which is similar to the time utilization survey used by DEGW, an international design consultancy co-founded by Francis Duffy, appears to be more useful for recording sedentary behaviors in workspaces. In contrast, the fixed route moving observer method still appears to be more effective for recording such fleeting behaviors as movement, interaction, and copresence (Rashid et al. 2005).

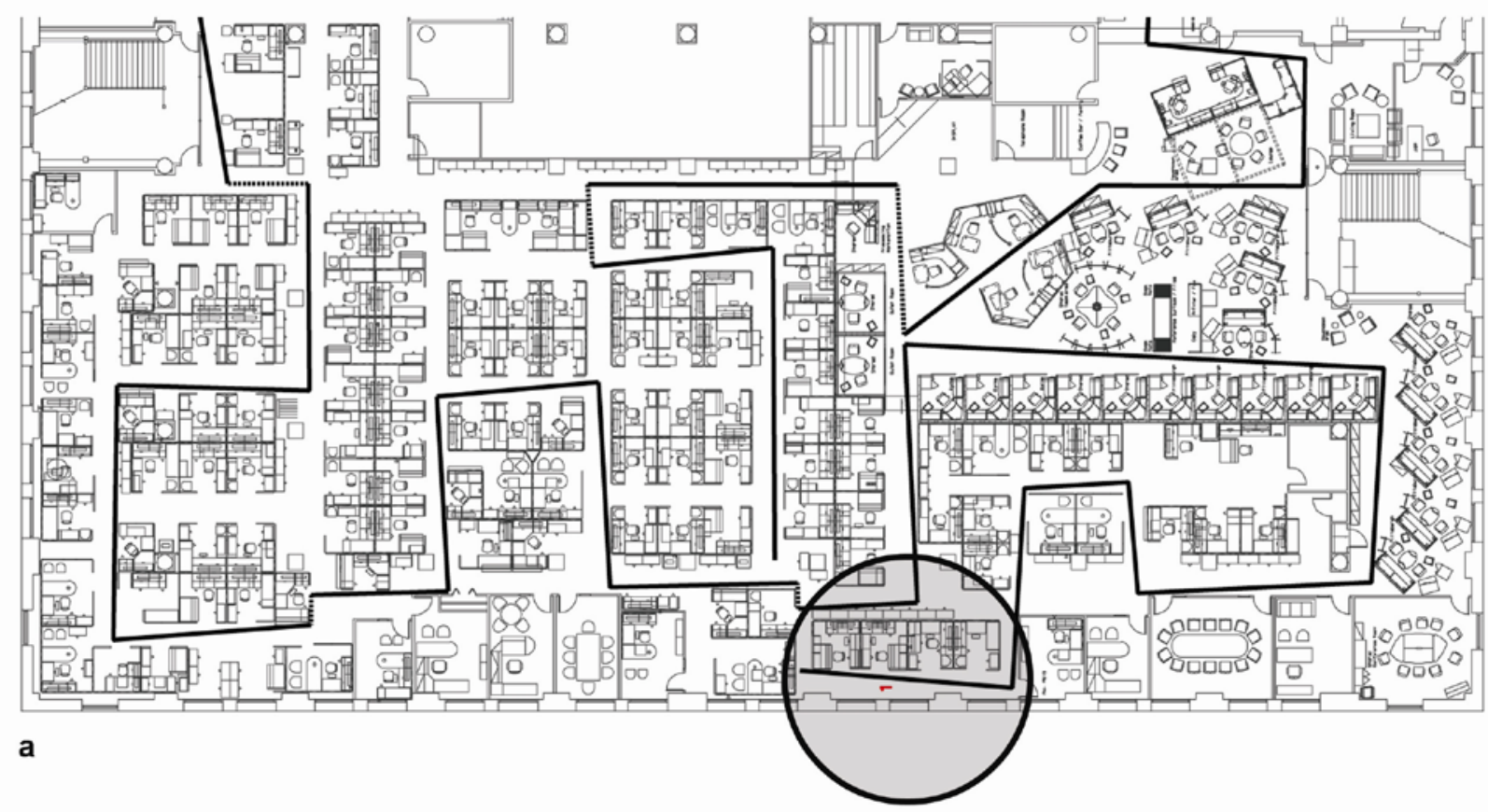

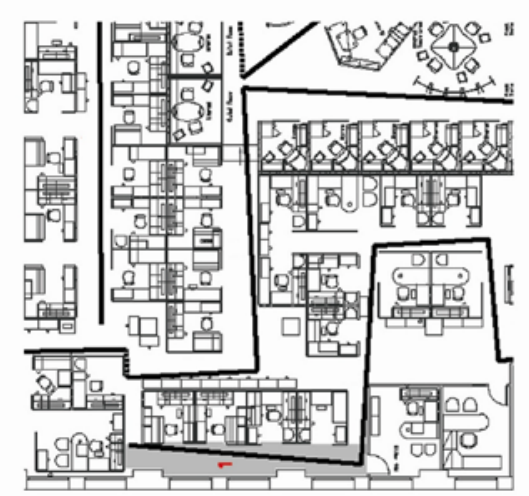

b

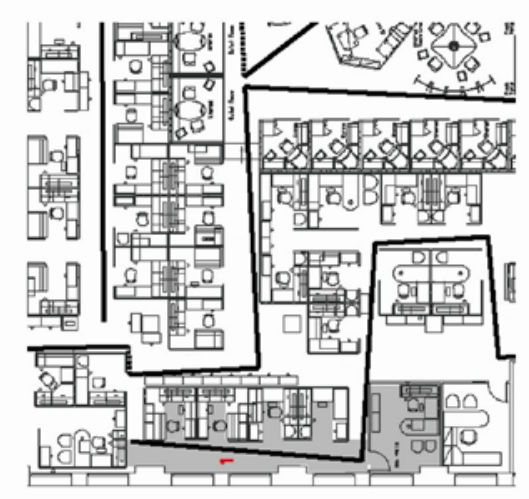

C

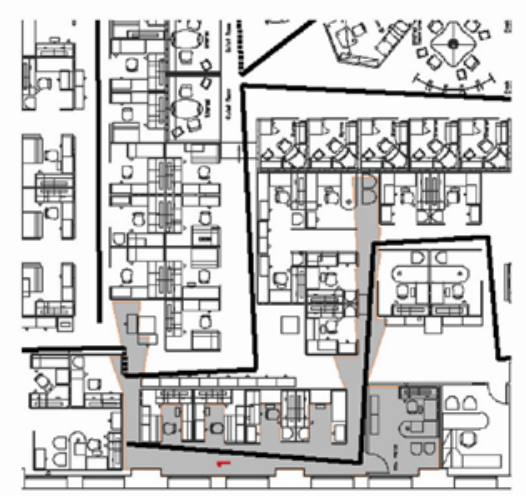

d

Figure 3: The behavioral observation techniques used in the study: (a) A part of the route for behavioral observations in one of the offices included in the study. (b) Movement is the number of people moving within an imagined band of space along an observation route. This band of space does not include any part of workspaces. (c) Face-to-face interaction is the number of people seen engaged in face-to-face interactions in the imagined band of space along a route segment as well as in the workspaces directly connected to the space. (d) Visible co-presence is the number of people located within the visual field of a route segment drawn at the eyelevel of an average person. 


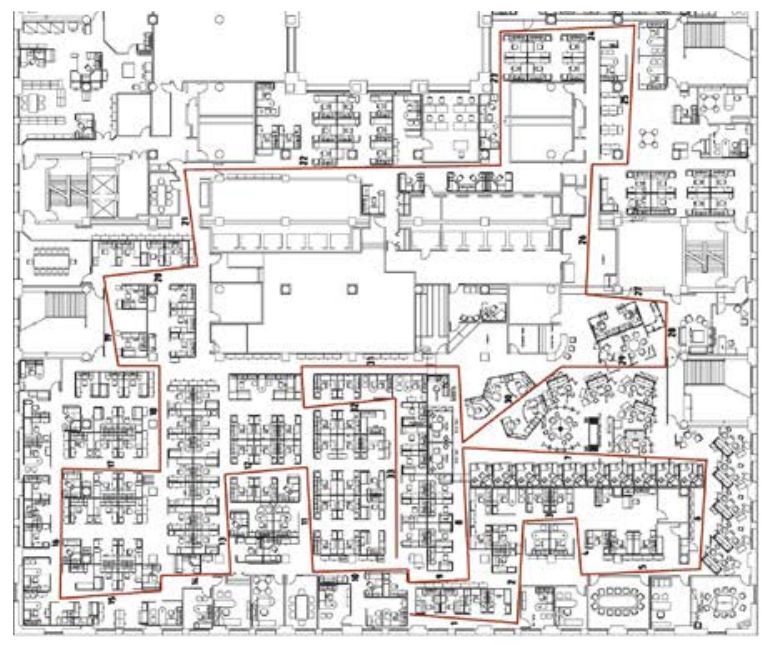

Figure 4a: The observation route in the old office.

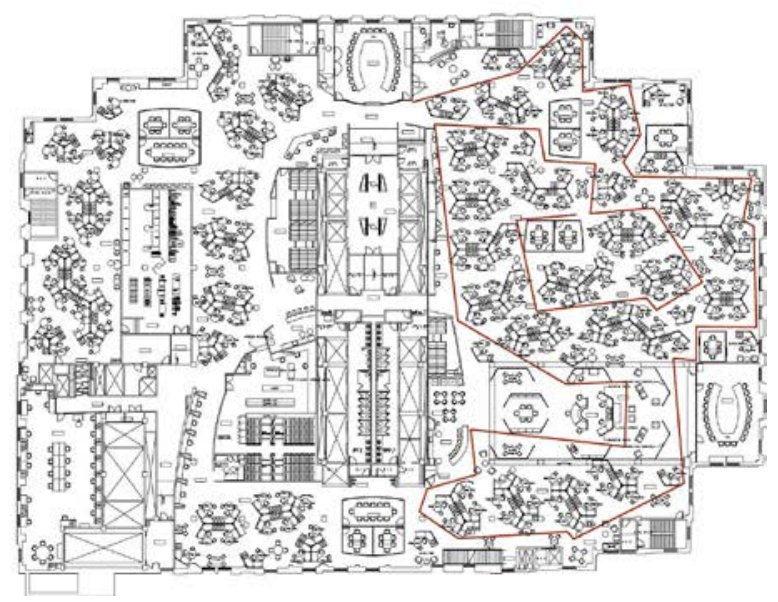

Figure 4b: The observation route in the new office.

\section{Survey questionnaire and measures}

Our survey questionnaire included multiple-item scales on privacy, job satisfaction, and commitment to organization. These scales were developed as a part of a larger study involving several government offices in the United States. The items of these scales were taken from scales that were tested for validity and reliability in previous studies. For example, the job satisfaction scale used in the study was based on the Job Satisfaction Survey (JSS) by Spector (1985, 1997). JSS is a 36 item, nine facet scale to assess employee attitudes about various aspects of the job. Each of these facets of the survey showed good internal consistency reliabilities. However, for our purpose we used only those facets of the scale that appeared to be more relevant to our larger study as well as to the present study. Hence, the internal consistency of our job satisfaction scale was tested separately. Likewise, the internal consistency our privacy and organization commitment scales were tested as well, for some other existing scales were modified to create these scales. All three scales showed good internal consistency for our larger sample (Wineman, et al. 2005). For the sample of this study, these scales showed good internal consistency as well. Cronbach's alpha for the privacy, job satisfaction, and organizational commitment scales were 0.63 , 0.72 and 0.838 , respectively.

The items included in each scale were as follows:

Privacy

I do not mind visual/physical control by supervisors.

I have enough privacy from others.

I have adjustable workspace to increase privacy.

Co-Workers cannot hear my conversations.

Co-Workers cannot hear my telephone conversations.

I have enough privacy to do my job well. 


\section{Job Satisfaction}

There is no bickering and fighting at work.

I enjoy my co-workers.

Communications seem good at work.

I like the things I do at work.

I enjoy my job.

I feel that I know what is going on in organization.

I do not have too much to do at work.

My work assignments are fully explained.

There is not much paperwork.

I sometimes feel that job is meaningless.

Rules/procedures makes job simple.

My efforts are seldom blocked by red tape.

The goals of organization are clear for me.

\section{Individual Commitment to organization}

My organization inspires the best performance.

I would accept any job within the organization to stay.

I am willing to go beyond what is expected to help the organization be successful.

I talk up the organization as a great place to work.

My values and organization's values are similar.

I am proud to tell others I am part of the organization.

I am glad that I chose this organization over others.

This is the best of all possible organizations to work for.

I care about the fate of the organization.

Respondents were asked to indicate on a 5-point scale, ranging from -2 (strongly disagree) to +2 (strongly agree), their agreement with each statement.

\section{Respondents and their workspaces}

At the old office, 35 people responded to the survey. Among them, 8 (22.9\%) were managers (low-level to senior managers), 16 (45.7\%) were professionals, 8 (22.9\%) were administrative staff that included one trainee, and the other three $(8.6 \%)$ did not mention their position or role. Among the respondents, there were 12 (34.3\%) males and 21 (60\%) females, and the other 2 (5.7\%) did not mention their sex.

At the new office, 86 people filled in the survey. Out of which 78 worked in the old office. However, only 29 out of 78 responded to the pre-move survey in the old office. Among the respondents, 6 (20.7\%) were managers, 14 (48.3\%) were professionals, 4 (13.8\%) administrative staff, and the other 4 (13.8\%) did not mention their position or role. There were 9 (31\%) males and 17 (58.62\%) females, and the other 3 (10.3\%) did not mention their sex. 
In other words, there were three major groups of respondents - professionals, administrative staff, and managers - at each of our sites. The size of each group expressed as percentage of the total number of respondent remained similar at these sites. The distribution of sex at these sites was also consistent.

Of the 35 respondents at the old office, 20 (57\%) occupied partitioned offices with panels above eyelevel, 11 (31\%) occupied office with panels below eye-level, the rest occupied a variety of other offices. Of the 29 respondents in the new open plan office, 19 (65.5\%) occupied offices with partition below eyelevel, 6 (20.7\%) occupied open spaces, and the rest occupied a variety of other offices. In other words, while in the old office only $31 \%$ of the respondents were visually exposed, in the new layout the number increased to $86 \%$.

\section{Analysis and Results}

According to the axial map analysis, the mean integration and connectivity values, the mean length of axial lines, and the length and number of axial lines per workspace of the old office were different from that of the new office (Table 1). These findings supported hypothesis 1, which had stated that different open plan offices would have different patterns of visibility and accessibility. Note here that the new office had higher mean integration, mean connectivity and mean length of axial lines, and lower length and number of axial lines per workspace making it both locally and globally more visible accessible than the old office. This was also true when the integration values of similar categories of spaces in both offices were compared. The spaces in the new office showed higher integration values in all categories (Table 2).

According to our observation data at both sites, people interacted most in individual workspaces (80.74\% in the old office and $84.31 \%$ in the new office), but the number of face-to-face interaction per workspace almost tripled in the new office (compare 0.692 in the old office to 1.95 in the new office) (Table 3). These findings supported our hypothesis 2 , which had stated that an open plan office with better visibility and accessibility would help generate more face-to-face interaction. In other words, even though spaces where most interactions occurred did not change in these offices, the number of interactions in these spaces increased significantly in the new office. According to the social relations perspective, this increase in interaction should help improve organizational climate. As a consequence, we observed a slight rise in the occupancy rate (i.e., the ratio of the number of occupied workspaces to the total number of workspaces expressed as a percentage) and the attendance rate (i.e., the ratio of the number of people present to the total number of occupied workspaces in the office expressed as a percentage) in the new office (Table 4).

In relation to the places of interaction, we found that people interacted more in all types of spaces except corridors or circulation spaces in the new office. The finding provided some support for our hypothesis 3. Since no significant changes occurred in the leadership, worker profile and management practices of the organization during the study period, we believe that people interacted more in most spaces in the new office because these spaces were generally more visible and accessible (Table 2). However, interactions in the corridors of the new office probably had decreased due to increased visibility and accessibility of these spaces as well. It is possible that people did not want to interact in the corridors of the new office 
because they felt uncomfortable talking to others standing next to a workstation with no enclosing partitions.

The regression analysis of the three spatial attributes and movement showed significant positive correlations between movement and the spatial variables for both the old and new offices taken together. However, for the old office only the correlations were insignificant but positive; and for the new office only they were significant and positive (Table 5). Additionally, the analysis showed significant negative correlations between integration and copresence and between connectivity and copresence for both cases taken together, but showed insignificant correlations between the same variable for each office taken separately. In contrast, the regression analysis showed no significant correlations between the spatial variables and interaction either for each office taken separately or for both offices taken together. In sum, the effects of spatial variables on spatial behaviors were not always consistent, thus providing only partial support for our hypothesis 4 .

We used independent-samples t-test in order to compare the significance of the differences between the means of perceived privacy, organizational commitment, and job satisfaction at the old and new offices. According to the Leven's test for equality of variance, the significance value of the statistic in all three cases was greater than 0.10 . Therefore, we assumed that the old and new offices had equal variances for the scales. The analysis showed that the means of all three scales increased after the move to the new office. Among the three scales, the change in perceived privacy was significant $(p=0.00)$; the change in organizational commitment was somewhat significant $(\mathrm{p}=0.08)$; and the change in job satisfaction was insignificant ( $\mathrm{p}=0.12$ ) (Table 6). In other words, our findings provided some support for hypothesis 6 but not for hypothesis 5, indicating that the many opportunities of interactions in an open plan office with more visibility and accessibility should result in higher organizational commitment, if not job satisfaction. Hypothesis 7 was also supported by the correlational analysis, which showed significant correlations between perceived job satisfaction and commitment to organization at each office, as well as both offices taken together (Table 7). Hypothesis 8 was partly supported by our findings, since significant increase in perceived privacy in the new office was accompanied by somewhat significant increase in perceived commitment to organization and insignificant increase in job satisfaction (Table 6). Although hypotheses 5, 6 \& 8 were not fully confirmed by the current study, we observed significant correlations among perceived privacy, job satisfaction, and individual commitment to organization for the old and new samples taken together. In other words, the general sense that greater perceived privacy could cause greater job satisfaction and commitment to organization as proposed in hypothesis $\mathbf{8}$ seemed to be a valid one.

\section{Discussion}

In this study, we compared the old open plan office with the new open plan office of a government organization. First, we wanted to describe the visibility and accessibility of these offices. Although both the old and new offices are open-plan offices, we predicted that the visibility and accessibility of these offices would be different. Second, we wanted to see how any differences in visibility and accessibility would affect spatial behaviors in these offices. We studied three behaviors - movement, visible 
Table 1: Summary of the spatial analysis of the old and new offices using space syntax

\begin{tabular}{|l|l|l|l|l|l|l|l|l|}
\hline & $\begin{array}{l}\text { Total no. of } \\
\text { workspaces }\end{array}$ & $\begin{array}{l}\text { Total no. of } \\
\text { axial lines }\end{array}$ & $\begin{array}{l}\text { No. of axial } \\
\text { lines per } \\
\text { workspace }\end{array}$ & $\begin{array}{l}\text { Sum of the } \\
\text { lengths of all } \\
\text { axial lines - } \\
\mathrm{ft}(\mathrm{m})\end{array}$ & $\begin{array}{l}\text { Length of axial } \\
\text { lines per } \\
\text { workspace - } \\
\mathrm{ft}(\mathrm{m})\end{array}$ & $\begin{array}{l}\text { Mean } \\
\text { Connectivity }\end{array}$ & $\begin{array}{l}\text { Mean } \\
\text { Integration } \\
\text { of axial lines } \\
-\mathrm{ft}(\mathrm{m})\end{array}$ \\
\hline Old Office & 244 & 253 & 1.037 & $8449(2576)$ & $34.62(10.55)$ & 3.51 & 1.24 & $33.39(10.18)$ \\
\hline New Office & 226 & 106 & 0.469 & $7210(2198)$ & $31.90(9.73)$ & 5.25 & 1.52 & $68.03(20.74)$ \\
\hline
\end{tabular}

Table 2: Integration values of different categories of spaces in the old and new office layouts described using the axial map analysis

\begin{tabular}{|l|l|l|l|}
\hline & \multicolumn{3}{|c|}{ Mean Integration } \\
\hline & Workstations & Circulation Spaces & Common Areas \\
\hline Old Office & 1.19 & 1.44 & 1.37 \\
\hline New Office & 1.48 & 1.55 & 1.55 \\
\hline
\end{tabular}

Table 3: Interactions in the office settings

\begin{tabular}{|c|c|c|c|c|c|c|}
\hline & \multicolumn{4}{|c|}{ Interactions at different locations } & \multirow[b]{2}{*}{$\begin{array}{l}\text { All Locations } \\
\text { along the route }\end{array}$} & \multirow{2}{*}{$\begin{array}{l}\text { Interaction per } \\
\text { workspace }\end{array}$} \\
\hline & $\begin{array}{l}\text { Individual } \\
\text { workspaces }\end{array}$ & $\begin{array}{l}\text { Designated areas and/or } \\
\text { meeting rooms }\end{array}$ & Corridors & $\begin{array}{l}\text { Common and/or } \\
\text { service areas }\end{array}$ & & \\
\hline Old Office & 109 (80.74\%) & 15 (11.11\%) & $7(5.18 \%)$ & $4(2.96 \%)$ & $135(100 \%)$ & 0.69 \\
\hline New Office & 215 (84.31\%) & 17 (6.67\%) & $3(1.17 \%)$ & $20(7.84 \%)$ & $255(100 \%)$ & 1.95 \\
\hline
\end{tabular}

Table 4: Workspace occupancy data of the office settings

\begin{tabular}{|c|c|c|c|}
\hline & $\begin{array}{l}\text { Total number of } \\
\text { workspaces }\end{array}$ & $\begin{array}{l}\text { Occupied Spaces (Occupancy as } \\
\% \text { of the total number of } \\
\text { workspaces) }\end{array}$ & $\begin{array}{l}\text { Number of People Present } \\
\text { (Attendance as \% of the number } \\
\text { of occupied spaces) }\end{array}$ \\
\hline Old Office & $195(100 \%)$ & $174(89.23 \%)$ & $104(60.05 \%)$ \\
\hline New Office & $131(100 \%)$ & $121(92.23 \%)$ & $62(67.23 \%)$ \\
\hline
\end{tabular}


Table 5: Correlations between spatial variables and observed behaviors in the office settings

\begin{tabular}{|c|c|c|c|c|c|c|c|c|c|}
\hline & $\begin{array}{l}\text { Integration } \\
\& \\
\text { Movement }\end{array}$ & $\begin{array}{l}\text { Connectivity } \\
\text { \& Movement }\end{array}$ & $\begin{array}{l}\text { Length \& } \\
\text { Movement }\end{array}$ & $\begin{array}{l}\text { Integration } \\
\& \\
\text { Interaction }\end{array}$ & $\begin{array}{l}\text { Connectivity } \\
\text { \& Interaction }\end{array}$ & $\begin{array}{l}\text { Length \& } \\
\text { Interaction }\end{array}$ & $\begin{array}{l}\text { Integration } \\
\& \\
\text { Copresence }\end{array}$ & $\begin{array}{l}\text { Connectivity } \\
\& \\
\text { Copresence }\end{array}$ & $\begin{array}{l}\text { Length \& } \\
\text { Copresence }\end{array}$ \\
\hline Old Office & 0.33 & 0.22 & 0.24 & -0.25 & -0.22 & -0.13 & -0.18 & -0.16 & -0.13 \\
\hline New Office & $0.57 * *$ & $0.69 * *$ & $0.53 * *$ & -0.13 & -0.17 & -0.12 & 0.16 & 0.01 & -0.03 \\
\hline Aggregate & $0.51 * *$ & $0.48 * *$ & $0.39 * *$ & -0.15 & -0.13 & 0.11 & $-0.3 * *$ & $-0.38 *$ & -0.19 \\
\hline
\end{tabular}

** Significant at the 0.01 level

* Significant at the 0.05 level

Table 6: Means of perceived privacy, job satisfaction and commitment to organization at the old and new offices with independent samples tests

\begin{tabular}{|c|c|c|c|c|c|c|c|c|c|c|}
\hline & \multicolumn{2}{|c|}{ Old Office } & \multicolumn{2}{|c|}{ New Office } & \multicolumn{2}{|c|}{$\begin{array}{l}\text { Levene's Test for } \\
\text { Equality of } \\
\text { Variances }\end{array}$} & \multicolumn{4}{|l|}{ t-test } \\
\hline & $\mathrm{N}$ & Mean & $\mathrm{N}$ & Mean & F & Sig. & $\mathrm{t}$ & $\mathrm{df}$ & $\begin{array}{l}\text { Sig. (2- } \\
\text { tailed) }\end{array}$ & $\begin{array}{c}\text { Mean } \\
\text { Difference }\end{array}$ \\
\hline Individual privacy & 35 & 3.69 & 29 & 4.26 & .40 & .53 & -3.49 & 62 & .00 & .57 \\
\hline Job satisfaction & 35 & 2.24 & 29 & 2.46 & .08 & .77 & -1.57 & 62 & .12 & .22 \\
\hline $\begin{array}{l}\text { Individual commitment to } \\
\text { organization }\end{array}$ & 35 & 2.12 & 29 & 2.44 & .01 & .93 & -1.79 & 62 & .08 & .32 \\
\hline
\end{tabular}

Table 7: Zero-order correlations among different measurement scales of environmental perception

\begin{tabular}{|l|r|r|r|r|r|r|r|r|r|}
\hline & \multicolumn{2}{|c|}{ Both offices taken together } & \multicolumn{3}{|c|}{ Old Office } & \multicolumn{3}{|c|}{ New Office } \\
\hline & 1 & 2 & 3 & 1 & 2 & 3 & 1 & 2 & 3 \\
\hline 1. Individual privacy & 1 & & & 1 & & & 1 & & \\
\hline 2. Job satisfaction & $.39\left(^{* *}\right)$ & & & $.52(* *)$ & & & $.12(\mathrm{~ns})$ & & \\
\hline 3. Individual commitment to organization & $.25(*)$ & $.62(* *)$ & 1 & .26 & $.63(* *)$ & 1 & $.07(\mathrm{~ns})$ & $.56(* *)$ & 1 \\
\hline
\end{tabular}

** Correlation significant at the 0.01 level (2-tailed)

* Correlation significant at the 0.05 level (2-tailed)

ns - Correlation not significant 
copresence, and face-to-face interaction. In this case, we predicted that the office with greater accessibility and visibility would show higher movement and visible copresence and would generate more face-to-face interaction. In addition, we also predicted that in both the old and new offices we would see more movement, visible copresence and face-to-face interaction in more accessible and visible spaces. In other words, the underlying effects of space on these behaviors would be consistent in these offices despite their differences. Finally, we wanted to know if there were any changes in individual perception of privacy, job satisfaction, and commitment to organization due to the move from the old office to the new office. From a social relations perspective, we predicted that higher social interaction would lead to higher job satisfaction and greater commitment to organization in the office with greater accessibility and visibility, and that job satisfaction and commitment to organization would be correlated. From a socio technical perspective, we suggested that though the office with greater accessibility and visibility would help generate more social interaction, job satisfaction and commitment to organization would increase only if perceived privacy increased in this office.

The study at the old office was conducted about one year before the move, and the study at the new office was conducted more than one year after the move. The study at each office had three parts. In the first part, the space syntax techniques were used to describe accessibility and visibility of each layout. In the second part, field observations were conducted to collect behavioral data. In the third part, questionnaire surveys were conducted to gather self-reported data on individual privacy, satisfaction, and commitment to the organization.

In accordance with hypothesis 1, our space syntax analysis showed that the layouts of the old and new open plan offices were different in terms of visibility and accessibility. In accordance with hypothesis 2 , where we had predicted that more accessibility and visibility would help improve interaction, our field observations found more face-to-face interaction in the new office. Our field observations also found that face-to-face interactions did not increase at all places in the new office as was predicted in hypothesis 3. For example, in response to the fact that most people did not have enclosing partitions around workstations, face-to-face interaction in the corridors and/or circulation spaces dropped in the new office. In other words, our results showed a change in the interaction culture of the organization, both in terms of the amount and location of interactions after it moved to the new office.

The effects of space on all types of observed behaviors were not consistent as was predicted in hypothesis 4. Movement was the only variable that had significant positive correlations in both cases showing that as accessibility and visibility of a space increased so did the number of people moving in the space. This is very much in line with previous space syntax findings (Hillier, 1996; Peponis et al., 1997a; Rashid \& Zimring, 2005a). In contrast, the effects of space on both visible copresence and face-to-face interactions were inconsistent, suggesting that in a work environment these behaviors could be more influenced by organizational culture and functions than by such spatial attributes as accessibility and visibility (Rashid et al., 2006).

From a social relations perspective, hypotheses 5 \& 6 predicted that higher face-to-face interactions in the office with greater accessibility and visibility would have a positive effect on organizational climate. Consequently, people would have higher job satisfaction and would be more committed to their organization. Our study showed that while both perceived satisfaction and commitment to organization increased in the new office, only the latter increase was statistically somewhat significant. The reason for 
this may be that in an office with greater accessibility and visibility individuals develop higher sense of communal ownership but relatively lower personal satisfaction and identification. Zalesny and Farace (1987) also reported similar findings. Our study also showed that job satisfaction and commitment to organization were correlated as was predicted in hypothesis 7. This is interesting in the light of the finding that increasing social interaction did not lead to significant changes in job satisfaction and individual commitment to organization in the new office. More simply, our study finding suggests that the relationship between job satisfaction and individual commitment to organization may not depend on social interaction.

Finally, from a sociotechnical perspective hypothesis $\mathbf{8}$ predicted that higher perceived privacy would lead to higher job satisfaction and commitment to organization. Our study showed significant increase in perceived privacy, somewhat significant increase in commitment to organization, and insignificant increase in job satisfaction in the new office. The fact that perceived privacy increased in the new office despite have more visibility and accessibility is very interesting. We know that accessibility and visibility may explain some variance in perceived privacy as shown in previous studies (e.g., Rashid \& Zimring, 2005a), but the current study points to the fact that there are probably many other ways to achieve privacy even in a very open plan office.

With regards to hypothesis 8, our study also showed that perceived privacy, job satisfaction and commitment to organization were positively correlated to one another when both offices were considered together in the analysis. The finding is interesting, because earlier we observed that significant increase in perceived privacy was not accompanied by significant increase in perceived job satisfaction and commitment to organization in the new office. The finding may suggest that although design changes may not affect perceived job satisfaction and commitment to organization, the underlying effect of perceived privacy on perceived job satisfaction and commitment to organization existed both before and after design changes.

Our findings regarding hypotheses $7 \& 8$ may point to a research design problem related to the measurement scales of privacy, job satisfaction, and commitment to organization. While there are no better ways to gauge individual's perceived privacy, job satisfaction and commitment to organization than to ask her directly, the reliability of individual assessment about her environmental perception is often difficult to estimate. To mitigate the problem, as researchers we often build a scale containing many statements to ensure that nothing important is left out of the scale that may potentially affect individual perception. While the process is appealing, it may prevent us from developing any causal relations and obscure issues that are more important. We did not observe changes in perceived job satisfaction and commitment to organization due to design changes at higher significance levels as predicted, maybe because these scales contained several statements unrelated to design. Future studies should try to develop simpler measures to study the effects of design, and then see how these measures are related to the more complex multi-faceted scales like the ones we used in this study. To seek out these design-relevant measures of environmental perception, it may be necessary for researchers to perform elaborate ethnographic studies at study sites.

Though our prospective research design allowed us to see how design changes could affect behavior and environmental perception, the number of people who responded to our questionnaire survey both before and after the move remained small. Due to the small size, we were unable to see how sex, status, job type 
and length of time with the organization might interact with design changes to affect perceived privacy, job satisfaction, and commitment to organization. For example, previous studies showed that individual perceptions and reaction to environmental changes varied with organizational positions (Becker, 1981; Campbell et al., 1970; Rapoport, 1982; Zalesny \& Farace, 1987). Additionally, in order to strengthen our study, we could have included a control group in the research design who experienced relatively little or no changes in design before and after the move. Such a group would have allowed us to study if the changes in environmental behavior and perception were in fact due to design changes or not. Furthermore, in this and most other similar studies, the overall environmental changes including changes in the aesthetic qualities, and managerial attitudes and philosophy have often confounded the effects of more instrumental design changes. Future research design may study reactions to changes in the physical and aesthetic qualities of the environment as well as managerial changes. Closer attention to all other changes in work environment should provide stronger tests for reactions to environmental changes.

Despite its limitations, the study is important because it uses three categories of variables - individuals' perception, spatial behaviors, and layout attributes - in its analytic framework. A prospective research study involving the same three categories of variables of the present study does not exist in the environment design and behavior literature. In this sense, this study makes a basic contribution to the field. The study is also important for it does not depend only on self-reported data like many other environment and behavior studies. It uses the objectively defined layout attributes of offices with observational and questionnaire data. In addition, studies of environmental perception that use relational attributes such as those defined by space syntax are also rare.

Overall, we can draw several conclusions from the study. First, not all open plan offices are equally accessible and visible. Second, despite different visibility and accessibility, the effects of space on patterns of movement may remain the same in offices. That is, we may observe more people moving in more accessible and visible spaces. Third, not all behaviors are equally affected by design changes. For example, visible copresence and face-to-face interaction in offices may be more affected by organizational culture and functions than movement. Fourth, design changes may affect the culture of interaction at workplaces in several ways. For example, change from an open plan office with enclosed workspace to another open plan office with open workspaces may not only generate higher number of interactions, but these interactions may also redistribute themselves in space as a result of design changes. Fifth, improvement in perceived privacy is possible even when design changes increase visibility and accessibility in workplaces. Finally, the underlying effects of perceived privacy on job satisfaction and commitment to organization may persist even in conditions with significant design changes. This study and its conclusions should help designers and decision-makers to make prudent decisions regarding workplace design changes, and future researchers to make more informed research designs. The success of any future effort to make effective design changes may, indeed, depend on achieving some of the conditions where the predictions regarding space, behavior and perceptions investigated in this study are fulfilled. 


\section{References}

Allen T J, 1970 “Communication networks in R \& D Laboratories” R \& D Management 1 (1) 14-211

Bechtel R B, 1976 Enclosing Behavior. Stroudsburg, PA: Dowden, Hutchinson, \& Ross

Becker F D, 1981 Workspace: Creating Environments in Organizations. New York: Praeger

Berkowitz L, 1956 “Group norms among bomber crews: Patterns of perceived crew attitudes, 'actual' crew attitudes, and crew liking related to aircrew effectiveness in Far eastern combat” Sociometry, 19, $141-153$

Bobele H K, Buchanan P J, 1979 “Building a more productive environment” Management World 8 (1) 8

Bovard E W, 1951 "The experimental production of interpersonal affect" Journal of Abnormal and Social Psychology, 46, 521 -528

Brennan A, Chugh J S, Kline T, 2002 "Traditional versus open office design: A longitudinal field study" Environment and Behavior 34 (3) 279-299

Campbell J P, Dunnette M D, Lawler E E, Weick K E, 1970. Managerial Behavior, performance, and effectiveness. New York: McGraw-Hill

Cangelosi V E, Lemoine L F, 1988 "Effects of open versus closed physical environment on employee perception and attitude" Social Behavior and Personality 16, 71-77

Chapman LJ, Campbell DT, 1957 “An attempt to predict the performance of three-man teams from attitude measurements” Journal of Social Psychology, 46, 277-286

De Croon E, Sluiter J, Kuijer P P, Frings-Dresen M, 2005 “The effect of office concepts on worker health and performance: a systematic review of the literature” Ergonomics 48(2) 119-134

Cross R, Borgatti S P, 2002 "Making invisible work visible: Using social network analysis to support strategic collaboration” California Management Review 44 (2) 25-46

Festinger L, Schacter S, Back K, 1950 Social Pressures in Informal Groups. Standford, CA: University Press

Gifford R, 1997. Environmental Psychology: Principles and Practice. Boston: Allyn \& Bacon

Gifford R, 2002. Environmental Psychology: Principles and Practice (3 ${ }^{\text {rd }}$ ed.). Colville, WA: Optimal Books

Grajewski T, 1992. Interaction in the work environment. Unpublished Doctoral Dissertation, University College London, London

Gullahorn J T, 1952 "Distance and friendship as factors in the gross interaction matrix" Sociometry 15, 123-134

Hall E, 1966. The Hidden Dimension. Garden City, N. Y.: Doubleday

Hillier B, 1996. Space is the machine. Cambridge, UK: Cambridge University Press

Hillier B, Hanson J, 1984. The social logic of space. Cambridge, UK: Cambridge University Press 
Hillier B, Grajewski T, 1987. The application of space syntax to work environments inside buildings. Unpublished Report, Unit for Architectural Studies, University College London, London

Hillier B, Penn A, 1991 "Visible colleges: structure and randomness in the place of discovery" Science in Context 4 (1) 23-49

Hillier B, Penn A, 1992 "The social potential of buildings: space and the innovative milieu in scientific research laboratories” Proceedings of the Corporate Space and Architecture Conference, Paris

Holahan C J, Saegert S, 1973 "Behavioral and attitudinal effects of large-scale variation in the physical environment of psychiatric wards” Journal of Abnormal Psychology 82, 454-462

Homans G C, 1950. The Human Group. New York: Harcourt, Brace \& World

Homans G C, 1954 “The cash posters: A study of a group of working girls” American Sociological Review 19, 724-733

Lawrence P R, Lorsch J W, 1967. Organization and Environment: Managing Differentiation and Integration. Cambridge, MA: Harvard University Graduate School of Business

Marans R W, Spreckelmeyer K F, 1982 “Evaluating open and conventional office design” Environment and Behavior 14 (3) 333-351

McCoy J M, 2002 "Work environments: The changing workplace” In R. B. Bechtel, \& A. Churchman (Eds.), Handbook of Environmental Psychology. New York: John Wiley, 443-460

Mittleman D, 1996 "The impact of physical environment on performance and satisfaction in the white collar office: An overview of the literature” Proceedings of the IFIP 8.4 Conference on the International Office of the Future, Tuscon AZ

Oldham G R, Brass D J, 1979 "Employee Reactions to an open-plan office: a naturally occurring quasiexperiment” Administrative Science Quarterly 24, 267-284

Oldham G R, Cummings A, Zhou J, 1995 "The spatial configuration of organizations: A review of the literature and some new research directions” Personnel and Human Resources Management 13, 1-37

Parsons H M, 1976 “Work environments” In I. Altman and J. F. Wohlwill (Eds.), Human Behavior and Environment: Advances in Theory and Research, Vol.1. New York: Plenum

Penn A, Desyllas J, Vaughan L, 1997 “The space of innovation” Proceedings of the Space Syntax Symposium, University College London, London

Peponis J, Wineman J, Rashid M, Bafna S, Kim S H, 1998 "Describing Plan Configuration According to the Covisibility of Surfaces” Environment and Planning B: Planning and Design 25, 693-708

Peponis J, Wineman J, Bafna S, Rashid M, Kim S H, 1998a "On the Generation of Linear Representations of Spatial Configuration” Environment and Planning B: Planning and Design 25, 559576

Peponis J, Wineman J, Rashid M, Bafna S, Kim S H, 1997 “On the Description of Shape and Spatial Configuration Inside Buildings: Convex Partitions and Their Local Properties” Environment and Planning B: Planning and Design 24, 761-781 
Peponis J, Ross C, Rashid M, 1997a "The Structure of Urban Space, Movement, and Copresence: The Case of Atlanta” Geoforum 28(3-4)341-358

Powell R M, 1952 "Sociometric analysis of informal groups - Their structure and function in two contrasting communities” Sociometry 15, 367-399

Rapoport, A, 1982. The meaning of the built environment. Beverly Hills, CA: Sage Publications

Rashid M, Kampschroer K, Wineman J, Zimring C, 2006 "Spatial layout and face-to-face interaction in offices - A Study of the Mechanisms of Spatial Effects on Face-to-face Interaction" Environment and Planning B: Planning and Design 33 825-844

Rashid M, Craig D, Zimring C, Thitisawat M, 2006 "Sedentary and Fleeting Activities and Their Spatial Correlates in Offices,” Proceedings of the 37th Annual Conference of the Environmental Design Research Association (EDRA), Atlanta, GA, 2006

Rashid M, Zimring C, 2005 “On Psychosocial Constructs and Office Settings: A Review of the Empirical Literature," Proceedings of the Environmental Design Research Association (EDRA) 35 Conference, Vancouver, Canada

Rashid M, Zimring C, Wineman J, Flaningam T, Nubani L, Hammash R, 2005 “The Effects of Spatial behaviors and Layout Attributes on Individuals' Perception of Psychosocial Constructs in Offices” Proceedings of the Fifth International Space Syntax Conference, Delft, Netherlands

Spector P E, 1985 “Measurement of human service staff satisfaction: Development of the Job Satisfaction Survey” American Journal of Community Psychology 13, 693-713

Spector P E, 1997. Job satisfaction: Application, assessment, causes, and consequences. Thousand Oaks, CA.: Sage

Sundstrom E, 1987 "Work environments: Offices and factories” In D. Stokols and I. Altman (Eds.), Handbook of Environmental Psychology. New York: John Wiley \& Sons

Sundstrom E, Altman L, 1989 "Physical environments and work-group effectiveness" Research in Organizational Behavior 11, 175-209

Sundstrom E, Burt R, Kamp D, 1980. "Privacy at work: architectural correlates of job satisfaction and job performance” Academy of Management Journal 23, 101-117

Walker C R, Guest R H, 1952. The man on the assembly line. Cambridge, MA: Harvard University Press

Wineman J D (Ed.), 1982. Environment and Behavior: Office Design and Evaluation I \& II, 14, 3 \& 4.

Wineman J D, Serrato M, 1998 “Facility design for high-performance team” Supporting work team effectiveness: Best management practices for fostering high performance Eds Eric Sundstrom and Associates, San Francisco, CA: Jossey-Bass

Wineman J, Rashid M, Zimring C, Flaningam T, 2003. Final Report - GSA High Performance Workspace, Ann Arbor, MI: University of Michigan.

Whyte W H, 1956. The Organization Man, New York: Simon and Schuster 
Zalesny M D, Farace R V, 1987 “Traditional versus open offices: a comparison of sociotechnical, social relations, and symbolic meaning perspectives” Academy of Management Journal 30, 2, 240-259 